\title{
Comparison of pretreatment characteristics and treatment outcomes for alcohol-, cocaine-, and multisubstance-dependent patients.
}

\author{
Ashwin A. Patkar \\ Thomas Jefferson University \\ Charles C. Thornton \\ Thomas Jefferson University \\ Paolo Mannelli \\ Thomas Jefferson University \\ Keyin P Hill Hill additional works at; https:/jidc.jefferson.edu/phbfp \\ Harvard Longwood Psychiatry Residency Training Program \\ Part of the Psychiatry Commons \\ EdwardGottheil myhow access to this document benefits you
}

Recommended Citation

Satkar, Ashwin A.; Thornton, Charles C.; Mannelli, Paolo; Hill, Kevin P.; Gottheil, Edward; Vergare,

Michael J.; and Weinstein, Stephen P., "Comparison of pretreatment characteristics and

treatment outcomes for alcohol-, cocaine-, and multisubstance-dependent patients." (2004).

Department of Psychiatry and Human Behavior Faculty Papers. Paper 43.

https://jdc.jefferson.edu/phbfp/43

This Article is brought to you for free and open access by the Jefferson Digital Commons. The Jefferson Digital Commons is a service of Thomas Jefferson University's Center for Teaching and Learning (CTL). The Commons is a showcase for Jefferson books and journals, peer-reviewed scholarly publications, unique historical collections from the University archives, and teaching tools. The Jefferson Digital Commons allows researchers and interested readers anywhere in the world to learn about and keep up to date with Jefferson scholarship. This article has been accepted for inclusion in Department of Psychiatry and Human Behavior Faculty Papers by an authorized administrator of the Jefferson Digital Commons. For more information, please contact: JeffersonDigitalCommons@jefferson.edu. 
Authors

Ashwin A. Patkar, Charles C. Thornton, Paolo Mannelli, Kevin P. Hill, Edward Gottheil, Michael J. Vergare, and Stephen P. Weinstein 


\section{Comparison of Pretreatment Characteristics and Treatment Outcomes for Alcohol-, Cocaine-, and Multisubstance- Dependent Patients}

We investigated whether pretreatment characteristics and measures of outcome differed for alcohol-, cocaine-, and multisubstance-dependent patients receiving outpatient substance abuse treatment. One hundred and forty substance dependent individuals (32 alcohol, 76 cocaine, and 32 multisubstance) enrolled in a 12-week outpatient treatment program were compared across measures of addiction severity, personality, and treatment-readiness at admission. In-treatment, end-of-treatment and 9-month follow-up assessments of treatment outcome were then compared across the three groups. Outcome measures included reduction in problem severity, abstinence, retention, number of sessions attended, dropout, and counselor and patient ratings of treatment benefit. At admission, the multisubstance group had a higher proportion of positive urines, reported more severe drug, alcohol and psychiatric problems, and displayed higher impulsivity and anxiety scores than one or both of the other groups. However, multisubstance patients were more treatment ready in terms of adopting a total abstinence orientation than alcohol or cocaine patients. While a significant reduction in symptoms occurred for the total sample during treatment as well as at follow-up, comparisons of outcomes did not consistently favor any particular group. The three groups had equivalent improvements in eleven of fourteen duringtreatment and five of seven follow-up measures. Despite pre-treatment differences, in severity and treatment-readiness, outcomes were more similar than different for alcohol-, cocaine-, and multisubstance-dependent patients. Clinicians should be cautious about forecasting treatmentoutcomes for addicted patients based on their primary substances of abuse. 